\title{
De la comedia heroica barroca a la dieciochesca: apuntes sobre la renovación argumental del género en dos piezas sobre la Reconquista castellana
}

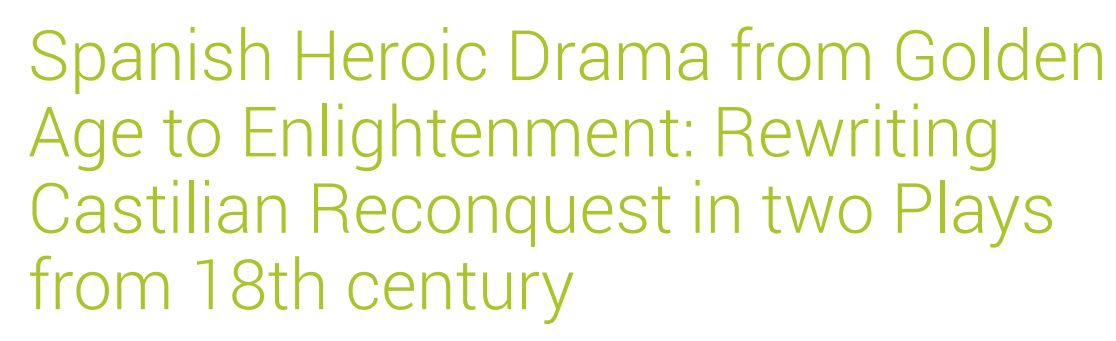

\author{
Alberto Escalante Varona \\ Universidad de La Rioja \\ ESPAÑA \\ alberto.escalante@unirioja.es
}

[Hipogrifo, (issn: 2328-1308), 8.2, 2020, pp. 233-253]

Recibido: 22-05-2020 / Aceptado: 19-06-2020

DOI: http://dx.doi.org/10.13035/H.2020.08.02.16

Resumen. En este artículo se ahonda en el proceso de modernización de la comedia heroica dieciochesca en los años 80-90 del siglo XVIII, una dinámica ya estudiada por la crítica, a partir de un condicionante hasta ahora poco tratado: la renovación de los argumentos históricos que tradicionalmente se escenificaban en los coliseos. Para ello, se comentan dos casos concretos: las comedias La afrenta del Cid vengada y La conquista de Madrid escritas por Manuel Fermín de Laviano. En primer lugar, se contextualizan ambas piezas en la tradición de reescrituras teatrales de las leyendas del Cid y Fernán González, de la que forman parte. A continuación, se indica cómo sus argumentos (extraídos de fuentes de los siglos XVI y XVII) introducen novedades en el tratamiento dramático que ambas historias habían desarrollado hasta entonces. Por último, se apunta la hipótesis de que estas comedias pueden ser ejemplo de una tendencia más extendida en dramaturgos coetáneos a Laviano, que recurren a argumentos legendarios poco 
representados hasta entonces para renovar la escena madrileña sin comprometer la tradición heroica.

Palabras clave. Ilustración; teatro popular; reescritura; épica medieval; «comedia nueva».

Abstract. In this paper, we address the modernization of Spanish heroic plays from the last twenty years of $18^{\text {th }}$ century, from a less studied critical perspective: rewritings of traditional legendary plots. For this purpose, we comment two plays written by Manuel Fermín de Laviano: La afrenta del Cid vengada and La conquista de Madrid. First, we contextualize both plays in the theatrical reception and depiction of the Medieval legends of the Cid and Fernán González. Then, we identify its literary resources from chronicles published in $16^{\text {th }}$ and $17^{\text {th }}$ centuries, to point how they introduce new dramatic constituents to both stories. At last, we offer as hypothesis how these plays could be an example of an extended trend in this period, as playwrights coetaneous to Laviano use less performed legendary plots in order to renew Spanish stage, but not compromising its heroic tradition.

Keywords. Enlightenment; Popular drama; Rewriting; Medieval epics; «comedia nueva».

\section{INTRODUCCIÓN}

El teatro histórico popular, a finales del siglo XVIII, experimenta una notable renovación escénica y de contenidos temáticos. Las reformas técnicas introducidas por las políticas teatrales del conde de Aranda' (desde 1767 hasta 1778) permiten la configuración plena de la escena dieciochesca: el conde intervino en la construcción de teatros en los reales sitios y en renovar los repertorios de comedias, restaurar las infraestructuras de los coliseos, financiar la sustitución de paños y cortinas por decoraciones pintadas, fomentar el uso de la música orquestal en las representaciones... Un plan de reformas que, si bien no se completó, sí se implantó lo suficiente como para cambiar de forma sustancial las formas de consumo del teatro en el Madrid del Setecientos. Por otra parte, un renovado patriotismo motiva el fomento del tratamiento escénico de leyendas españolas, lo que no solo se aprecia en el teatro neoclásico, explícitamente político², sino también en el popular. Si bien la tragedia neoclásica española comenzó su andadura con los autores 
clasicistas de la «primera generación arandiana», en los años 60-70, la modernización de la comedia heroica ${ }^{3}$, tomando los nuevos modelos de patriotismo trágico, tiene lugar en los años 80-90.

En este proceso de renovación, hay ejemplos textuales que nos permiten orientar una posible hipótesis sobre otra vía de reformulación de este teatro: una argumental. Sobre dos ejemplos de reescritura de relatos heroicos provenientes de una tradición registrada en crónicas y cronicones barrocos (las comedias La afrenta del Cid, vengada y La conquista de Madrid, de Manuel Fermín de Laviano, de las que comentaremos brevemente sus fuentes y constituyentes), trazaremos un panorama general en las comedias de otros dramaturgos como Moncín, Zavala y Rey, para rastrear cómo el proceso de modernización de la comedia heroica dieciochesca se llevó a cabo no solo en la adaptación de sus contenidos al ideal ilustrado, sino también en la representación escénica de episodios tradicionales que hasta entonces no eran frecuentes en las tablas. Con ello, se readapta la ineludible tradición épica a unos códigos escénicos y una práctica teatral profesional, para así contribuir a solventar el progresivo desinterés del público dieciochesco por la comedia barroca.

\section{LA COMEDIA HEROICA A FINALES DEL SIGLO XVIII: ESTADO DE LA CUESTIÓN}

\subsection{La refundición como procedimiento renovador de la cartelera}

La crítica, ya desde el fundamental estudio de $\mathrm{Cook}^{4}$, ha señalado la progresiva falta de interés por la comedia barroca ${ }^{5}$ en la sociedad de finales del siglo XVIII. Tomando por ejemplo a Calderón, el comediógrafo barroco más representado del siglo, sus comedias pasan de ocupar casi un tercio de las representaciones de temporada, durante la primera mitad de siglo, hasta constituir apenas una décima parte a comienzos de la década de los 80. La taquilla tampoco es cuantiosa: en lo referente a la afluencia del público, dato que puede medirse por las recaudaciones obtenidas, las reposiciones de estas piezas no suelen superar el $50 \%$ de la recaudación total que era capaz de obtener cada coliseo según su número máximo de localidades ${ }^{6}$. Esta situación es extrapolable a otros dramaturgos áureos como Lope ${ }^{7}$, Moreto, Solís, Vélez de Guevara y Rojas Zorrilla.

3. McClelland (1970, pp. 537-568) fue quien expuso primero el concepto de «modernización del drama heroico» para diferenciar las nuevas realizaciones dramáticas de este género en el siglo XVIII con respecto a las barrocas que las antecedieron. Sobre este concepto y los dramaturgos y textos indicados por McClelland realizamos nuestra aproximación en el presente estudio.

4. Cook, 1959

5. Palacios Fernández, 1988, pp. 66-92.

6. Andioc, 1976, pp. 17-30.

7. López Martín, 2015 y 2019. 
Aceptando que el teatro barroco se representa en el siglo XVIII «como recurso para completar la programación, cuyo plato fuerte eran las contemporáneas comedias de magia, militares y heroicas ${ }^{8}$, esto implica que, desde de la mentalidad de taller de escritura que orientaba la producción de textos teatrales, se hizo preciso sustituir la tragicomedia barroca por otras soluciones más exitosas. Estas pasan por la creación de nuevos géneros (proliferan el teatro musical y el sainete) y por el reaprovechamiento textual de los caudales de comedias manuscritas de las compañías, con el fin de ofrecer aparentes novedades que motivasen la asistencia del público.

La refundición se realiza tanto por motivos de contenido como estéticos, relativos a la forma dramática. Es un proceso de actualización: «es el resultado de intentar poner al día, por razones diversas, una producción teatral clásica cuyo significado se adapta a cada momento para hacerlo vigente»⿳⺈. En la segunda mitad del siglo XVIII la refundición se dirige principalmente a un público no sustancialmente burgués: el grueso de la programación de la cartelera corresponde a géneros populares de la llamada «comedia de espectáculo» ${ }^{10}$, en la que progresivamente se incluirán elementos poéticos de los géneros neoclásicos de nuevo cuño.

8. Pedraza Jiménez, 2007, p. 280.

9. Álvarez Barrientos, 1995.

10. Término propuesto por Cañas Murillo, 1990, p. 60. Cabe señalar que este marbete de «comedia de espectáculo» lo toma Cañas de Bretón de los Herreros, quien denominaba «drama nuevo de espectáculo» a las piezas históricas o sentimentales que destacaban por su aparato escénico. Por tanto, su empleo retrospectivo hacia la dramaturgia dieciochesca puede resultar anacrónico, aunque debemos tener en cuenta que Bretón formula estas etiquetas en base a una tradición heredada y que aún pervivía en su juventud: algunas comedias históricas o heroicas de Laviano se representaron hasta entrado el siglo XIX, al menos hasta 1825 (Menéndez Pidal, 1924, p. 569; la falta de carteleras al respecto limita nuestra aproximación). Por tanto, debemos hacer varias aclaraciones. Cañas Murillo establecía su clasificación genérica del teatro dieciochesco en base a su configuración escénica: distinguía así entre un teatro en el que el texto era subsidiario al efecto especial (y abarca, así, subgéneros temáticos de forma ecléctica: comedia heroica, militar, de santos, de magia...), y los géneros neoclásicos, de escenografía más austera. Palacios Fernández (2012, p. 161) distinguía entre teatro espectacular, romancesco y costumbrista: modalidades que categorizan tendencias compositivas. Las comedias heroicas y militares, de santos y de magia entrarían en el cupo del teatro espectacular. Si tuviésemos que escoger una clasificación propia de la época, teniendo en cuenta la imprecisión crítica que ya entonces existía al respecto, deberíamos diferenciar entre la comedia «de teatro» y la «sencilla»: conceptos que denotan que la configuración escénica de la representación era la que orientaba la composición de las piezas, ajustándolas a las capacidades técnicas del coliseo, así como la planificación de la cartelera por parte de las compañías, ya que las comedias «de teatro» eran más caras de representar pero aseguraban una afluencia mayor de público. Por coherencia con nuestro trabajo, solo emplearemos el término «comedia heroica», puesto que nuestro estudio se circunscribe a tres comedias propias de este subgénero: independientemente de que denominemos a su etiqueta mayor como «comedia de espectáculo», «teatro de espectáculo» o «comedia de teatro». 


\subsection{La renovación de la comedia heroica tradicional a finales del siglo XVIII}

La comedia popular que se escribe y representa a lo largo del siglo XVIII no es una simple continuación, sin innovación alguna, de la que se representaba en el siglo $\mathrm{XVII}^{11}$. La poética del teatro popular reside ante todo en la práctica, que tiene un fuerte poso tradicional. Por consiguiente, el teatro histórico dieciochesco es claramente deudor de los rasgos efectistas del teatro epigonal barroco. No obstante, durante el último tercio del siglo cambian las mentalidades sociales (dramaturgos, autores $^{12}$ y público), las condiciones materiales de representación, las circunstancias de composición. Las comedias históricas nuevas son un género diferente, y como tal ha sido tratado por la crítica. Prima la escenografía espectacular, que llega a condicionar la estructura dramática y argumental de las comedias para focalizar en la consecución de golpes de efecto y escenas climáticas.

La comedia heroica ${ }^{13}$ es uno de los géneros de moda durante los años 80 y 90. El repentino gusto del público por estas cuestiones, si bien proveniente de una nutrida tradición barroca ${ }^{14}$, responde en el siglo XVIII a un sentimiento patriótico que permea en la sociedad y que se materializa de muy diversas formas, desde políticas teatrales por instancias oficiales hasta el costumbrismo castizo del sainete. Todo el teatro histórico del siglo XVIII es fundamentalmente político, como reacción patriótica ${ }^{15}$, y estas cuestiones influirán en consecuencia sobre la comedia heroica tradicional, acentuando sus contenidos patrióticos y actualizando sus rasgos poéticos a las circunstancias técnicas de representación.

11. Véase Álvarez Barrientos, 1992: coincidimos con sus aportaciones en lo relativo a cómo la comedia popular, en sus múltiples y variadas manifestaciones, carecía de una poética estructurada y registrada por escrito; antes bien, se perpetuaba por la tradición, transmitida en la propia práctica teatral por las compañías.

12. Empleamos este término en el sentido que se le da en el siglo XVIII como «director de compañía».

13. También designada como comedia militar (Palacios Fernández, 2012, p. 161), comedia histórica (Caso González, 1988), heroico-militar (Fernández Cabezón, 1990) o de moros y cristianos (Narganes, 2010).

14. Uno de los casos paradigmáticos de modernización del género heroico en el teatro dieciochesco lo constituye la comedia militar de tema contemporáneo: representaciones de hazañas bélicas realizadas por monarcas y generales europeos, representantes del despotismo ilustrado. Especialmente interesante es la producción dramática de Comella y de Zavala y Zamora al respecto: véanse los estudios de Campos (1969), McClelland (1970), Fernández Cabezón (1990) y Angulo Egea (2006).

15. El estado de la cuestión es muy amplio, de modo que a continuación ofrecemos algunas fichas bibliográficas fundamentales: Andioc (1970) en su estudio introductorio a su edición de Raquel, de Vicente García de la Huerta; Cañas Murillo (2000) y su estudio sobre los temas políticos de Raquel en la configuración de sus personajes; Sala Valldaura (2005) y su estudio monográfico sobre la tragedia neoclásica; Torrecilla (2008) en su estudio sobre los elementos políticos de la literatura española dieciochesca, con especial atención a la tragedia neoclásica; y los estudios preliminares de Lorenzo Álvarez (2018) y Durán López (2018) a sus ediciones, respectivamente, de El Pelayo de Jovellanos y Los hijosdalgo de Asturias de Vargas Ponce. 


\section{NUEVOS ARGUMENTOS PARA HÉROES TRADICIONALES: LAS HAZAÑAS DEL CID Y LAS CONQUISTAS DE FERNÁN GONZÁLEZ EN TRES COMEDIAS DE MANUEL FERMÍN DE LAVIANO}

En este panorama, el dramaturgo madrileño Fermín de Laviano es uno de los principales exponentes de la comedia heroica, con predilección por los hechos de la Reconquista. Como tal fue conocido ya en su época y ridiculizado, como escritor de «tragedias que hacen reír» ${ }^{16}$. No evita la oportunidad de representar las leyendas de dos de los grandes héroes épicos castellanos: el Cid y Fernán González. Para ello, remite a fuentes barrocas en las que se reescriben los relatos tradicionales: de este modo, y como veremos, consigue adaptar sus contenidos a los códigos poéticos de la comedia de éxito a finales del siglo XVIII, sin contradecir por ello a una tradición bien asentada en el imaginario popular.

\subsection{La afrenta del Cid, vengada: las victorias de Rodrigo Díaz y la afrenta de Corpes}

El argumento tradicional de la leyenda del $\mathrm{Cid}^{17}$ fue construido durante el Medievo a partir de sucesivas incorporaciones de episodios que conforman un todo reconocible por el público. Durante la Modernidad Temprana, el relato se transmite principalmente a través del romancero y de crónicas breves: la Crónica popular del Cid y la Crónica particular del Cid ${ }^{18}$. I gualmente, las crónicas de Ocampo, Morales, Mariana, Pellicer y otros autores sirven para fijar textualmente la tradición durante los decenios posteriores hasta finales del siglo XVIII. El teatro también fue un escaparate para la representación de estas gestas. Vega García-Luengos ${ }^{19}$ realizó una completa revisión del estado de la cuestión de comedias áureas en las que se representa alguno de los episodios de la leyenda. En un total de veintidós piezas dramáticas, los núcleos argumentales se distribuyen de la siguiente manera: juventud del Cid y muerte del conde Lozano (3 comedias); conflicto sucesorio, cerco

16. Con este apelativo, Juan Pablo Forner ridiculizó a Laviano con motivo de unos versos que imprimió con motivo del nacimiento de los infantes gemelos en septiembre de 1783. Hemos estudiado este caso en Escalante Varona, 2019a.

17. El concepto de «argumento tradicional», o «esquema argumental recurrente», lo tomamos de Rodiek, 1995, pp. 22-25, quien a su vez lo toma de Frenzel, 1980, p. 71. Al plantear el estudio de la leyenda del Cid y su transmisión desde la perspectiva tematológica, el relato tradicional estaría conformado por los aquellos elementos de la acción, personajes, temas, recursos y motivos que permanecen inmutables en grado suficiente como para resultar reconocibles y pertenecientes a dicho relato en sucesivas reformulaciones narrativas a lo largo del tiempo.

18. Respectivamente, Coronica del Çid Ruy Diaz, 1498 (también conocida como Cronica del muy esforçado cauallero el Cid Ruy Diaz Campeador, título que tuvo en varias de sus reediciones posteriores), y Chronica del famoso cauallero Cid Rui Diez Campeador, 1593

19. Vega García-Luengos, 2007. 
de Zamora y jura de Santa Gadea (9 comedias); conquista de Valencia y muerte del Cid (1 comedia); cobardía de Martín Peláez (3 comedias); afrenta de Corpes (2 comedias); otros episodios (4 piezas) ${ }^{20}$. Como puede comprobarse, el mayor interés creativo durante los siglos XVI y XVII recae en el episodio de la jura de Santa Gadea; si bien no es el más exitoso en las tablas, lo que le corresponde a las Mocedades del Cid de Guillén de Castro, en su primera parte, centrada en la juventud del héroe. Con todo, Vega señala una tendencia general y progresiva a lo largo del siglo hacia la parodia y lo burlesco, así como a un desplazamiento de los hechos heroicos y solemnes del Cid, hasta entonces nucleares, hacia los márgenes argumentales, poniéndose en consecuencia el foco en los sucesos sentimentales, cortesanos y de enredo que hasta entonces habían sido periféricos y apócrifos ${ }^{21}$.

En lo referente al siglo XVIII, Vega22 indica la escasez de textos originales: una tragedia anónima titulada Don Rodrigo de Vivar (copiada, según su único manuscrito conservado, en 1784), la comedia de Laviano La afrenta del Cid, vengada, y la de José Concha La diadema en tres hermanos (sin fecha, probablemente en torno a 1790). También se localiza una refundición titulada Las mocedades del Cid y las bodas de Jimena (sin fecha) sobre la primera comedia de Guillén de Castro, y una traducción del Cid de Corneille, fechada en 1803, que a su vez partió de dicho texto de Guillén. A esto tendríamos que añadir El más heroico español, también de Concha (impresa en 1797). Coincidimos, pues, en que la producción original de textos parece ser escasa en el siglo XVIII, pero consideramos que este estado de la cuestión puede ampliarse con un rastreo exhaustivo de los fondos de comedias.

En todo caso, llama la atención la comedia de Laviano, una de las pocas originales localizadas, porque en ella se representa un episodio hasta entonces muy infrecuente en las tablas barrocas, fuera de la comedia de Francisco Polo El honrador de sus hijas y de la burlesca y anónima Los condes de Carrión: la afrenta de Corpes y el resarcimiento del honor del Cid tras el juicio a los infantes cobardes. En 1783, año de estreno de La afrenta del Cid, vengada23, ya se había publicado por primera vez el Cantar de mio Cid, por parte de Tomás Antonio Sánchez, en 1779. Sin embargo, Laviano no consulta esta fuente: por el contrario, remite a las citadas Crónica popular y Crónica particular, que no son sino refundiciones tardías de crónicas

20. El caballero sin nombre, de Mira de Amescua; Los tres blasones de España, de Coello y Rojas; El auto sacramental del Cid; Mojiganga del Cid.

21. Vega García-Luengos, 2007, pp. 68-69.

22. Vega García-Luengos, 2007, pp. 72-73, n. 34

23. El estreno tuvo lugar el 21 de febrero (Andioc y Coulon, 2008, p. 617). Se conserva en varios apuntes manuscritos: cuatro en la Biblioteca Histórica de Madrid (BHM: Tea 1-3-7), uno en la Biblioteca Nacional (BNE: Ms. 15880) y otro en la Biblioteca de la Universidad de Sevilla (A 250/074(1)). Cuenta con edición, realizada por Ratcliffe (2002), quien consulta los manuscritos de BHM; por este motivo, ya que no contamos aún con una edición verdaderamente crítica, elaborada sobre todos los testimonios, preferimos consultar el testimonio BHM-A, que contiene las aprobaciones de la censura para su representación. 
compuestas en la tradición historiográfica alfonsí, adaptadas al formato editorial del libro de caballerías ${ }^{24}$. Solo en ellas encuentra contenidos novelescos en su trama paterno-filial, que resultarían atractivos para el público. Véase el siguiente ejemplo, tomado de la Crónica popular, comparado con la primera jornada de La afrenta del Cid vengada; se aprecia cómo Laviano se refiere a la escena en las almenas que no se recoge en el Cantar ${ }^{25}$, sino en la Crónica ${ }^{26:}$

24. Este tipo de crónicas breves, sobre diferentes episodios históricos y bíblicos, constituyeron un lucrativo negocio editorial durante los siglos XVI y XVII, hasta su prohibición en 1766 por orden del censor Juan Curiel. Véanse los estudios de Lopez (1993), García Collado (1997 y 2017), Infantes (2014), Cacho Blecua (2017) y Escalante Varona (2019b) sobre las circunstancias del pleito que Curiel mantuvo con los impresores Antonio Sanz e Hilario Santos, quienes, con la prohibición, perdían una importante fuente de ingresos. 25. Si bien en el Cantar se menciona el temor de los infantes, no se describe este episodio de manera tan prolija en detalles, ambientado en las almenas del castillo: «Fuerzas de Marruecos Valencia vienen cercar: / Cinquenta mill tiendas fincadas ha de las cabdales. / Aqueste era el Rey Bucar, sil' oviestes contar. / Alegravas' el Cid è todos sus varones, / Que les crece la ganancia grado al Criador. / Mas, sabet, de cuer les pesa à los Infantes de Carrion: / Ca veyen tantas tiendas de Moros de que non avien sabor. / Amos ermanos apart salidos son: / Catamos la ganancia è la pérdida non: [...] Oyó la poridad aquel Muño Gustioz: / Vino con estas nuevas à Mio Cid Ruy Diaz el Campeador [...]» (Sánchez, Colección de poesías castellanas anteriores al siglo XV, tomo I, pp. 317-318, vv. 2322-2335). Igualmente, téngase en cuenta que las crónicas breves sobre el Cid y Fernán González son reescrituras de crónicas tardomedievales: véase Puyol y Alonso, 1911, pp. 3-10, y Cacho Blecua, 2017, pp. 291-295, quienes señalan, respectivamente, cómo la Cronica del muy esforçado cauallero el Cid Ruy Diaz Campeador y la Estoria de Fernán González, de 1509, toman como base la Crónica abreviada de España, o Valeriana, de mosén Diego de Valera. En el caso del Cid, Laviano no remite al Cantar, cuya transmisión en el siglo XVIII estaba concentrada en ámbitos eruditos (véase nuestro estudio: Escalante Varona, 2019c), sino a la tradición más extendida, que era la que se consigna en las historias de España derivadas de la tradición historiográfica alfonsí. 26. Citamos el texto de la Crónica popular del Cid en su impresión de 1533. Actualizamos la ortografía y la puntuación de los textos que citamos en este artículo, siguiendo criterios de edición generalizados en los estudios dieciochistas actuales. En el caso de las crónicas medievales, modernizamos para facilitar la lectura del texto. En cuanto a la Historia de Segovia, que citaremos más adelante, remitimos a la edición digital disponible en el Centro Virtual Cervantes, en una versión actualizada ortográficamente. 
El rey Búcar aportó con gran flota y salió de las naos con grandes gentes, y mandó assentar su real en el campo de cuartel. Y estando el Cid ordenando la forma que había de tener para dar la batalla, y a los otros reyes que con él venían, llegaron a él don Suero González y los infantes de Carrión, sus sobrinos, teniendo ya determinado en sus malas voluntades el mal consejo ya dicho. [...] Entonces el Cid tomó a los infantes por las manos, y a Suero González, y subiólos a la más alta torre del alcázar, y mostróles el gran poder que los moros traían, y parecían tantas tiendas y tantos tendejones puestos que era cosa maravillosa de mirar. Y el Cid comenzó de reír y mostrar que le placía mucho de la muchedumbre de tiendas que los moros traían. Mas Suero González y sus sobrinos habían muy gran miedo, como quiere que lo encubrían. Al descender de la torre, como el Cid iba delante, dijo el tío a los sobrinos: «Si en esta lid entramos, nunca a Castilla volveremos». Y ellos, no se guardando, oyólo Nuño Gustos y él lo dijo al Cid. Y cuando lo oyó, pesólo mucho [...]

(fol. $32 r-v)$ sale Nuño Señor, si queréis gozar

del más propio y más ameno objeto de diversión, que subáis conmigo os ruego a las almenas: veréis un ejército agareno tan copioso y bien armado, que es de la vista recreo cuando ofrece al corazón el placer del vencimiento. CID Tú sí que hablas, fuerte Nuño,

con el lenguaje que aprecio, [...]

Don Suero, Diego, Fernando, venid conmigo, y veremos este espantoso enemigo que amedrenta vuestros pechos.

[...]

SUERO ¡Ay, sobrinos! No es posible

que nuestras vidas salvemos, pues el poder del alarve según se advierte es inmenso. [...]

CID Bájanse sin esperar, como es justo, mis preceptos, dejándome en las almenas, y están los tres con misterio hablando a solas. Oigamos, aunque algún pesar oiremos. (cuadernillo 1, fols. 10r-13r)

Rodrigo Díaz aparecerá caracterizado en esta comedia con los rasgos superficiales e intercambiables de todo héroe de la comedia de espectáculo: soberbio, altivo e impetuoso, pero también buen padre, buen guerrero, gobernante ejemplar. Esta caracterización será extrema para contraponerla con acierto a la de los antagonistas: Ios condes de Carrión y su tío Suero. El episodio de su cobarde huida frente al león corresponderá a la prehistoria de la comedia: seguramente, porque llevarlo a escena con la verosimilitud requerida resultaría casi imposible. Pero este gesto, relatado retrospectivamente en la primera jornada, servirá para dibujarlos de forma negativa ante un público que ya está predispuesto a depositar en ellos su aversión, pues conocería su ultraje gracias a los romances y los mencionados relatos caballerescos breves. De estos últimos, y no del Cantar, se extrae el episodio que da comienzo a la comedia. Búcar, caudillo moro, desembarca en Valencia para tomar la ciudad y vengar así la muerte de su hermano a manos del Cid. Cuando Rodrigo Díaz lleva a sus yernos y al tío de estos a lo alto de las almenas de su castillo para contemplar con agrado la llegada del enemigo, los de Carrión apenas pueden contener su pavor y traman alguna manera de evitar combatir (véase el ejemplo citado arriba). 
El resto de la comedia se desarrolla por los cauces esperados, propios de la leyenda tradicional. La caracterización de los condes se debatirá entre la apariencia y la realidad, entre su notoria cobardía (exagerada y tratada de forma casi paródica en la comedia ${ }^{27}$ ) y la aparente valentía que demuestran en combate, hasta que la afrenta de Corpes termina por presentarlos como merecedores de todo oprobio. Efectivamente, los desaires cometidos por los de Carrión están motivados por los éxitos públicos del Cid, quien, pese a su orgullo, es digno depositario de tal fama, pues los ha logrado por mérito propio. La maldad de los condes es extrema y se dibuja con rasgos «femeniles»: los condes son acusados por parte del Cid y sus soldados de poseer un espíritu femenino, propio de una mala crianza carente de cualquier contenido militar:

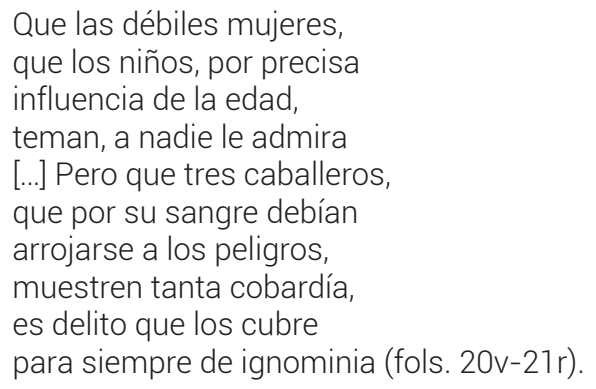

Mientras, doña Jimena instruye a sus hijas para que sean pacientes y sumisas. Así, las lisonjas y cariños proferidos por las mujeres hacia sus maridos hacen más imperdonables los maltratos que estos las infligen. Por ello, la familia del Cid solo se podrá resarcir por medio de la vía legal regia. El recurso del duelo, repudiado por la crítica (puesto que se trataba de una práctica prohibida por sanción rea|28), no es cuestionado en este caso por el reseñista del Memorial literario: cabe pensar que, en este caso, no era posible contradecir a una tradición fija que establece que los de Carrión fueron condenados públicamente en duelo de honor:

\begin{tabular}{|c|c|}
\hline $\begin{array}{l}\text { DIEGo Que no me mates tu ruego, } \\
\text { pues a los pies de mi Rey } \\
\text { humildemente confieso } \\
\text { mis delitos [...]. } \\
\text { RAMIRO Y VELA Detente, fuerte Alvar Fáñez. } \\
\text { [...] ya del duelo } \\
\text { has cumplido con las Leyes, } \\
\text { y pues confiesa sus yerros, } \\
\text { sea su mayor castigo } \\
\text { vivir y reconocerlos. }\end{array}$ & $\begin{array}{l}\text { SUERo Este sagrado me valga } \\
\text { contra tu furor [...]. } \\
\text { RAMIRO Y VELA Detente. } \\
\text { [...] ya está satisfecho } \\
\text { el honor del Cid, y tú, } \\
\text { como esforzado guerrero, } \\
\text { has cumplido exactamente } \\
\text { con el tuyo en el empeño. } \\
\text { (cuadernillo 3, fols. 23v-24r) }\end{array}$ \\
\hline
\end{tabular}

27. Podría tratarse de una herencia tonal procedente del tratamiento paródico hacia el episodio que ya se ha localizado en el teatro tardobarroco, tal y como hemos indicado previamente.

28. Consúltese, como testimonio de época, el «Discurso sobre el origen, uso y abolición de los duelos en España» publicado en el Memorial literario en enero de 1785. 
No es de extrañar que, con estas bases temáticas, unidas a un eficiente aparato escénico, La afrenta del Cid, vengada fuese uno de los mayores éxitos de Laviano desde su estreno en la conveniente fecha del Carnaval de 1783. Amparándose en la relevancia cultural del personaje y en su tradición, y adaptándolo a los códigos del género de la comedia de espectáculo, Laviano consigue conjugar en una misma comedia del Cid el respeto al relato medieval y la fórmula de éxito escénico del momento.

\subsection{La conquista de Madrid: las conquistas segovianas y el conde Fernán González}

La leyenda de Fernán González sigue unos cauces de evolución similares a los del Cid, si bien en el caso del conde castellano su caracterización tipológica pierde buena parte de su relevancia identitaria original ${ }^{29}$. Inicialmente adalid de la independencia castellana y de la rebeldía del condado contra León, tras la unificación de ambos reinos se intensifica su personificación como cruzado y guerrero santo, adscrito a los monasterios de San Pedro de Arlanza y San Millán de la Cogolla. Como guerrero, se convierte en caudillo de la cristiandad contra el islam, origen heroico de la patria española y buen modelo de comportamiento como noble y marido.

La recepción dramática del personaje en los Siglos de Oro es también similar a la del $\mathrm{Cid}^{30}$. El corpus de comedias localizado es cuantitativamente menor con respecto al del Cid, y en ellas es frecuente que se mezclen diferentes relatos de la vida del conde. En orden cronológico, en La libertad de Castilla, atribuida a Hurtado de Velarde, se representa tanto la exención del condado como la guerra castellana contra los musulmanes; lo mismo ocurre en El conde Fernán González, de Lope de Vega, si bien introduciendo el conflicto político y amoroso en el que participa la condesa doña Sancha; en la anónima Favores que hizo Dios al señor conde Fernán González se escenifican únicamente las hazañas milagrosas que originaron el monasterio de Arlanza; en la segunda jornada de La Virgen de la Fuencisla, escrita por Juan de Zabaleta ${ }^{37}$ y titulada La antigüedad de Segovia, se representa la conquista de Madrid a manos de los capitanes segovianos comandados por el conde y el rey Ramiro de León; en La más hidalga hermosura, de Calderón, Zabaleta y Rojas, se supedita el conflicto de la independencia de León a un enredo amoroso entre el conde y doña Sancha; en Lo que vale el oír misa, Mira de Amescua emplea al personaje del conde de forma tangencial en la leyenda de la condesa traidora; en Las amazonas de España, de Juan del Castillo, el relato del origen del monasterio de Arlanza está completamente deturpado con elementos apócrifos.

Este corpus, en continua ampliación, arroja interesantes conclusiones sobre la recepción dramática del personaje, una vez cruzamos estos datos con los referentes a las reposiciones de estas piezas en la cartelera del siglo XVIII. La comedia más

29. Pérez Priego, 1989.

30. Escalante Varona, 2016 y 2018.

31. Es una comedia escrita a tres manos, siendo cada jornada responsabilidad de un ingenio distinto: las tres jornadas tienen como nexo de unión la intervención milagrosa de la Virgen de la Fuencisla. Los otros autores son Sebastián de Villaviciosa y Juan de Matos Fragoso. 
exitosa fue La más hidalga hermosura, durante la primera mitad de siglo, seguida de La Virgen de la Fuencisla. El público, al igual que con el Cid, parece preferir el enredo amoroso y cortesano. Laviano, de nuevo, participa en el proceso de adaptación de una leyenda épica al código de la comedia de espectáculo. En el caso de Fernán González, firma El castellano adalid (1785) y La conquista de Madrid $(1786)^{32}$, en las que pone de nuevo en escena (tras la aportación de Zabaleta) las conquistas segovianas al mando del conde castellano.

La fuente consultada por Laviano para componer ambas comedias es la Historia de Segovia escrita por Diego de Colmenares en 1637. Colmenares defiende la historicidad de lo que entonces era tradición: la participación de linajes segovianos en hechos capitales de la restauración de España. De este modo, sitúa a Fernán González como caudillo de los capitanes segovianos Díaz Sanz y Fernán García que conquistaron Madrid, escalando heroicamente sus murallas. Así, el cronista segoviano potencia la relevancia histórica de su ciudad al relacionarla con el pasado épico castellano; compárense los siguientes ejemplos, en los que se prueba que Laviano representa el episodio contenido en la narración ${ }^{33}$.

\begin{tabular}{|c|c|}
\hline $\begin{array}{l}\text { [...] Quisiera el leonés volverse sin tentar a Madrid por } \\
\text { su fortaleza, y no poder conservarla; y porque el ejér- } \\
\text { cito estaba cansado, y el invierno cercano podía estor- } \\
\text { bar con nieves los pasos de las sierras. [...] Nuestros } \\
\text { capitanes Día Sanz y Fernán García la esforzaron con } \\
\text { tanto denuedo, que pidiendo alojamiento en el cerco } \\
\text { respondió el rey lo que refiere la tradición constante, [...] } \\
\text { que si tan denodados eran, fuesen a alojarse a Madrid. } \\
\text { [...] El conde acometió por la puerta del Sol, [...] a tiem- } \\
\text { po que nuestros segovianos impelidos de lo que el rey } \\
\text { les había dicho, habían escalado la torre de una puerta, } \\
\text { y enviado aviso al rey como ya tenían alojamiento en } \\
\text { Madrid y su alteza podía aposentarse en ella. }\end{array}$ & $\begin{array}{l}\text { ORDUÑ̃ No hay que añada } \\
\text { al dictamen de mi rey, } \\
\text { pues, siendo tan avanzada } \\
\text { la estación, no es tiempo propio } \\
\text { para empresas dilatadas. } \\
{[\ldots . .]} \\
\text { DíAZ Y así, Señor, pues que veis } \\
\text { que es solamente fundada } \\
\text { mi opinión en honor vuestro, } \\
\text { espero que sin tardanza } \\
\text { mandéis se establezca el sitio } \\
\text { o se arrimen las escalas. } \\
\text { [...] Señor, ¿dónde señaláis } \\
\text { a las tropas segovianas } \\
\text { su alojamiento? } \\
\text { RAMIRO En Madrid. [...] } \\
\text { Cuando las manda } \\
\text { un tan valiente caudillo, } \\
\text { es preciso señalarlas } \\
\text { un alojamiento digno } \\
\text { de su jefe y de su espada (pp. 11-12). }\end{array}$ \\
\hline
\end{tabular}

32. El castellano adalid se conserva en cinco apuntes manuscritos: tres en la Biblioteca Histórica de Madrid (BHM: Tea 1-97-1), uno en la Biblioteca Nacional (BNE: Ms. 15959) y uno en la Biblioteca de la Universidad de Sevilla (A 250/111(1)); su estreno fue el 25 de diciembre de 1785 (Andioc y Coulon, 2008, p. 660). Fue editada por Ratcliffe (2002), quien consulta los manuscritos BHM. La conquista de Madrid solo se conserva en una suelta impresa (Barcelona, Imprenta de Pablo Nadal, 1797); su primera representación documentada es del 18 de febrero de 1786 (Andioc y Coulon, 2008, p. 844).

33. Colmenares, Historia de la insigne ciudad de Segovia y compendio de las historias de Castilla, capítulo XI, secciones XI-XII. 
En el caso del relato de la conquista de Sepúlveda, ya existía una tradición textual que Colmenares aprovechó para su crónica. Por el contrario, no ocurre así con la toma de Madrid ${ }^{34}$. Laviano, ajeno a esta tradición textual, aprovecha solo la Historia de Colmenares como fuente para ambas comedias, pues contiene los relatos completos de las dos campañas de conquista. De este modo, un mismo texto cronístico refuerza la ilación entre ambas piezas.

En El castellano adalid, y más especialmente en La conquista de Madrid, la rivalidad castellano-leonesa constituye uno de los recursos base, pero no uno de los temas principales. Aunque Díaz Sanz, soldado segoviano, y Ordoño, capitán leonés, en La conquista de Madrid, son rivales, esto nunca se aplica a los comandantes de ambos ejércitos. Ramiro II y Fernán González se alían para hacer frente a un enemigo común: el musulmán. En esta guerra, Castilla ostenta la supremacía práctica: y si bien el conde está legitimado por sus múltiples éxitos en la guerra, para el rey esta es su primera campaña, por lo que carece de experiencia en combate. Sin embargo, esto no cuestiona en ningún momento la autoridad real: aunque inexperto en la lid, Ramiro II sigue siendo el líder cristiano, mientras Fernán González queda como caudillo militar 35 :

$\begin{array}{ll}\text { RAMIRO } & \text { Pues yo, Conde, }[. . .] \\ & \text { determiné destinar } \\ & \text { todo el poder de mi brazo } \\ & \text { a eclipsar las medias lunas. } \\ \text { Y como estoy cerciorado } \\ \text { de que solo vuestro nombre } \\ \text { causa al sarraceno espanto, } \\ \text { quise asegurar mis triunfos } \\ \text { con vos y vuestros soldados (p. 2). }\end{array}$

Díaz y Fernán son arrogantes y atrevidos a la par que valientes luchadores: Díaz, por ejemplo, será capaz de enfrentarse a su rey, con tal de obtener de él una actitud combativa ante sus dudas sobre la conveniencia de asediar Madrid («[...] No, gran Ramiro: no cuenta / la historia de vos que acaba / vuestro Militar empeño / en tan débil amenaza [...]», p. 12), en contraposición con la mesura timorata de la que hacen gala los capitanes leoneses («No es ofenderle / decir que tal vez se precia / con exceso de valiente, / además que cualesquiera / de nosotros es capaz / de emprender lo que él empresa», sostiene Ortuño sobre Díaz a sus espaldas, p. 24). Será el conde quien finalmente traslade el ímpetu guerrero de los segovianos al rey leonés, consiguiendo así que el ejército cristiano asalte Madrid:

34. Colmenares cita a fray Gonzalo de Arredondo como una de sus fuentes principales para relatar la conquista de Sepúlveda a manos de Fernán González y los capitanes segovianos; consúltese QuintaniIla, 1954, quien localiza la copia del manuscrito de Arredondo que consultó Colmenares, y que contiene el citado episodio. Sin embargo, Arredondo no consignó el relato de la conquista de Madrid, que Colmenares tuvo que construir a partir de otras fuentes aún no identificadas. Sobre las crónicas de Arredondo, consúltense los trabajos de Gómez Pérez, 1958, y Vaquero, 1987, entre otros.

35. Citamos por la suelta en la que se conserva la comedia. 


$\begin{array}{ll}\begin{array}{ll}\text { RAMIRO } \\ \text { CONDE }\end{array} & \text { ¿Qué haré Conde? } \\ & \begin{array}{l}\text { Conceder } \\ \text { lo que animosos os ruegan, } \\ \text { y esperar en Dios el triunfo } \\ \text { por precisa consecuencia. } \\ \text { ¿Eso dices? }\end{array} \\ \begin{array}{l}\text { RAMIRO } \\ \text { RANDE }\end{array} & \begin{array}{l}\text { Esto digo. } \\ \text { LAMIRO }\end{array} \\ & \text { Capitanes Viva Ramiro (p. 25). }\end{array}$

Por tanto, ningún rastro de la rebeldía medieval del conde, rasgo principal de su caracterización épica primitiva, se aprecia en su configuración como personaje. Así, la enemistad castellano-leonesa se trata solo como manifestación de la tópica caracterización arrogante de los héroes prototípicos de la comedia heroica. La comedia culminará con una sorprendente toma de la villa, con los actores escalando los inexpugnables muros y abriendo las puertas, dejando entrar a una muchedumbre ruidosa y furiosa de soldados. Previamente, una escaramuza mora habrá incendiado en escena las minas y cavas de Madrid por las que los cristianos pretendían entrar en la población; un efecto que causó sensación entre el público ${ }^{36}$.

Así, en La conquista de Madrid asistimos a un ejemplo de asimilación de un personaje épico a los códigos esquemáticos y prototípicos de la comedia de espectáculo dieciochesca. Lo que resta, en todo caso, es la caracterización del conde como guerrero cristiano contra el islam: caracterización que resulta idónea para la comedia heroica de finales del siglo XVIII. Al primar lo espectacular sobre la coherencia argumental, y al construirse los protagonistas heroicos a partir de caracteres tópicos e intercambiables, una leyenda de por sí tradicional y refrendada en una crónica sirve así como excusa para ofrecer una serie de artificios espectaculares que contribuyen al éxito en taquilla.

\section{LA RENOVACIÓN ARGUMENTAL COMO ESQUEMA DINÁMICO: APUNTES PARA UN PANORAMA GENERAL EN LA COMEDIA HEROICA DIECIOCHESCA}

En La afrenta del Cid vengada (1783) y las comedias de Fernán González, El castellano adalid (1785) y La conquista de Madrid (1786), Manuel Fermín de Laviano sigue un mismo patrón compositivo: recurrir a textos narrativos ampliamente difundidos para adaptar episodios hasta entonces poco frecuentes en la escena. No son los únicos casos en su carrera literaria. En Triunfos de valor y honor en la corte de Rodrigo (1779) ofrece una comedia palaciega sobre duelos de amor por la condesa de Lorena que tiene como fondo la leyenda de Florinda la Cava. En El cadalso para su dueño (1780) adapta la historia de los Pardo de Aragón y su participación en la conquista de Mequinenza. En La defensa de Sevilla (1781) muestra cómo los godos protegieron la ciudad bajo las órdenes de Sarmato, frente al asedio

36. «[...] se hallan en ella cautiverios y aventuras mujeriles, batallas, asaltos y una mina con pez ardiendo en sus paredes, sin saber cómo, y cuyas llamas hicieron poca impresión en Díaz Sanz, que entró por ella.» («La Conquista [...]», 1786, p. 409). 
musulmán. No hemos localizado otras comedias barrocas en las que se traten los mismos episodios, lo que implicaría que el tratamiento que hace Laviano de ellos es original en cuanto a que sería el primero en adaptarlos.

Este patrón podría ser representativo de una tendencia general en otros dramaturgos populares. Luis Moncín escribió Cómo defienden su honor las ilustres roncalesas (1784) y Hechos heroicos y nobles del valor godo español (1784), ambas novedades argumentales en la cartelera. Lo mismo ocurre en La defensa de Barcelona por la más fuerte amazona (1788), de Fermín del Rey. En la comedia La conquista de Mallorca (1792), Miguel Bover y Ramonell escenifica la recuperación de la ciudad a manos del rey Jaime I. Entre otras obras de Zavala y Zamora, destacamos cómo en Triunfar solo por la fe (1789) se muestran los hechos bélicos en Lara, que nunca antes se habían escenificado.

Para poder confirmar una hipótesis de que estos casos particulares responden a una tendencia general, a otra vía de modernización de la comedia heroica dieciochesca, debemos ampliar el corpus de textos para poder sustentar cuantitativamente nuestras afirmaciones. A priori, el progresivo desinterés del público hacia el «teatro antiguo español» puede ser el motor principal de este proceso renovador de argumentos. Nótese que la moda por la comedia heroica en el último tercio de siglo coincide con su mencionada modernización en forma y contenido ${ }^{37}$. Cabría pensar, pues, en una sustitución de una fórmula por otra, que podríamos ejemplificar en los casos de las leyendas del Cid y Fernán González y las comedias de Laviano. En ellas se escenifican hazañas poco frecuentes para el público de los coliseos, a través de un aparato escénico abrumador, enfocado ante todo en la recreación de asedios y batallas multitudinarias.

Sin embargo, si bien podemos apreciar tal patrón en la obra de Laviano, carecemos de datos y aproximaciones críticas suficientes como para sostener una relación causal: esto es, que estos ejemplos se encuadran en una práctica común y extendida a los dramaturgos populares de la época a modo de respuesta a una necesidad empresarial por sustituir la comedia antigua barroca. Para poder confirmar tal aproximación, es preciso trazar concomitancias y redes entre autores y textos, así como tener en cuenta otros elementos del contexto: el más interesante, un protonacionalismo español que se refleja especialmente en el teatro de la Villa, tanto culto como popular.

Aun así, otros ejemplos coetáneos que hemos señalado parecen apuntar hacia esa dirección. Los dramaturgos populares aprovechan todas las posibilidades escenográficas de los coliseos para así asegurar la afluencia del público, lo que les impele a emplear como base argumental los episodios legendarios de conquistas,

37. Remitimos de nuevo al estudio de McClelland, 1970, pp. 537-568. Si bien la comedia heroica no había desaparecido de la escena en la primera mitad de siglo, y constituía uno de los tipos de drama contra los que arremetieron los preceptistas neoclásicos, en el último tercio de siglo prolifera en la escena de la mano de autores como Moncín, Laviano, Zavala y Zamora, Valladares de Sotomayor, Rodríguez de AreIlano, Rey, etc. Así se explica, de hecho, que el personaje de don Eleuterio, de La comedia nueva (1792) de Leandro Fernández de Moratín, escriba su primera comedia (que Moratín ridiculiza) en el género heroico, el que está en boga en aquellos años. 
tomas de plazas y batallas campales. Y si bien la comedia histórica de tema heroico cuenta con un recorrido bien asentado en la escena áurea, también es cierto que lo que la caracteriza en el siglo XVIII es tanto su escenografía, producto de los avances técnicos de la época, como los contenidos de algunas de sus piezas, más cercanos a los planteamientos ilustrados.

Esto podría explicar que, en el caso del Cid y Fernán González, tengan un gran éxito no las comedias sobre enredos amorosos e intrigas palaciegas, sino aquellas en las que se entremezclan lances amorosos novelescos, intensos conflictos paterno-filiales y sorprendentes batallas y asedios a villas fortificadas. Para poder amoldar la tradición a las nuevas formas escénicas, hay que desechar los argumentos prototípicos y recurrir a episodios propicios para la representación de hechos bélicos: si son novedosos, ello sin duda contribuiría al interés del público hacia lo no visto hasta entonces. Pero esto no implica en absoluto un rechazo a la tradición. Las fuentes cronísticas áureas, que a su vez son refundiciones de crónicas medievales, siguen siendo textos muy difundidos, clave para remitir a versiones autorizadas sobre el pasado patrio. Al consultarlas y extraer de ellas los núcleos narrativos más apropiados para programar una función de comedia «de teatro», los dramaturgos populares también remitían necesariamente a una tradición textual bien conocida por el público y a la que no podían renunciar. En el reconocimiento reside buena parte del éxito de la pieza, más aún en el caso de relatos fundacionales plenamente asentados como verídicos en el imaginario colectivo, donde residen contenidos identitarios y modelos instructivos de comportamiento.

\section{CONCLUSIONES}

Tal y como la crítica ha señalado ${ }^{38}$, una revisión de la cartelera teatral de finales del siglo XVIII prueba el auge de la comedia heroica en este periodo: una reformulación de la comedia histórica según nuevos códigos escénicos derivados de las innovaciones técnicas producidas bajo el amparo del conde de Aranda, pensadas en principio para el teatro nobiliario pero que favorecieron igualmente al teatro popular. En este sentido, este hecho coincide con otro ya conocido por la crítica: la progresiva desaparición de piezas barrocas en la cartelera dieciochesca.

En este panorama, localizamos ejemplos de comedias en las que diversas leyendas de gestas y héroes de la Reconquista se representan adaptadas como comedias heroicas. Un ejemplo de ello lo constituyen tres comedias del dramaturgo madrileño Manuel Fermín de Laviano. En La afrenta del Cid, vengada (1783), El castellano adalid (1785) y La conquista de Madrid (1786) Ileva a escena las vidas y hazañas del Cid y Fernán González. Para ello, emplea crónicas de los siglos XVI y XVII como fuentes, para tomar de ellas narraciones de episodios poco comunes en las tablas: los ejemplos puntuales aquí recogidos (para no extender el análisis más allá de los límites de este artículo) son representativos del procedimiento compositivo que lleva a cabo Laviano en ambos textos completos, comprobable si se coteja su contenido con el de los textos cronísticos identificados como su fuente. De este

38. Véanse los estudios de McClelland, 1970, y Andioc, 1976, antes citados. 
modo, con la habilidad propia de un hombre de teatro, escoge solo aquellos núcleos narrativos más propicios para su escenificación: los que corresponden a hechos de asedios y toma de ciudades.

La acción creativa de Laviano ejemplifica el papel que adoptan los dramaturgos de la época en el proceso de reescritura y adaptación de la tradición a nuevos códigos de recepción y transmisión. Igualmente, puede indicar la existencia de una tendencia general en los talleres teatrales de la época hacia la renovación de los fondos de comedias heroicas por medio de la escritura de piezas basadas en episodios tradicionales con poca presencia en la cartelera de décadas anteriores. Diversas comedias heroicas de Zavala y Zamora, Fermín del Rey y Luis Moncín, entre otros, apuntan a esta tendencia hacia la renovación argumental. Todo ello sin comprometer en modo alguno la tradición. El dramaturgo puede innovar en la selección de núcleos narrativos inéditos o infrecuentes en la cartelera, pero no debe inventar nuevas historias, pues eso comprometería el contenido identitario e instructivo que debe transmitir toda pieza dramática histórica.

Los datos recogidos que apuntan a esta posible tendencia abren la puerta a nuevas investigaciones con el fin de plantear con solvencia una hipótesis de trabajo. Partiendo de revisiones bibliográficas sobre fondos de apuntes manuscritos, se cuantificará de qué manera los argumentos de las comedias heroicas de este periodo corresponden a narraciones infrecuentes en las tablas, lo que puede interpretarse como una respuesta profesional de los dramaturgos hacia la necesidad de las compañías teatrales por renovar su repertorio, ante el evidente desinterés del público por la comedia barroca ya clásica y aprovechando el éxito de la comedia heroica en este momento. De este modo, se podrá avanzar en el conocimiento de las circunstancias y vías de transmisión, recepción y evolución formal y temática de la tradición teatral barroca. Y, concretamente, en sus realizaciones de la comedia heroica dieciochesca, imbuida en su particular idiosincrasia profesional e ideológica.

\section{BibLIOGRAFÍA}

Álvarez Barrientos, Joaquín, «La teoría dramática en la España del siglo XVIII», Teatro. Revista de Estudios Teatrales, I, 1992, pp. 57-73.

Álvarez Barrientos, Joaquín, «Revisando el teatro clásico español: la refundición de comedias en el siglo XIX», en Historia y crítica del teatro de comedias del siglo XIX... y la burguesía también se divierte, coord. Ana Sofía Pérez-Bustamente Mourier, Alberto Romero Ferrer y Marieta Cantos Casenave, El Puerto de Santa María, Fundación Pedro Muñoz Seca, 1995, pp. 27-39.

Álvarez Barrientos, Joaquín, «El arte escénico en el siglo XVIII», en Historia del teatro español, vol. 2, Del siglo XVIII a la época actual, coord. Javier Huerta Calvo, Madrid, Gredos, 2003, pp. 1473-1518.

Andioc, René, «Introducción», en Vicente García de la Huerta, Raquel, Madrid, Castalia, 1970. 
Andioc, René, Teatro y sociedad en el Madrid del siglo XVIII, Madrid, Castalia, 1976.

Andioc, René, y Coulon, Mireille, Cartelera teatral madrileña del siglo XVIII (17081808), Madrid, Fundación Universitaria Española, 2008.

Angulo Egea, María, Luciano Francisco Comella (1751-1820). Otra cara del teatro de la Ilustración, Alicante, Universidad de Alicante, 2006.

Cacho Blecua, Juan Manuel, «La primera crónica breve caballeresca en el siglo XVI», en «La razón es aurora». Estudios en homenaje a la profesora Aurora Egido, ed. Ángeles Ezama, José Enrique Laplana, María Carmen Marín, Rosa Pellicer, Antonio Pérez Lasheras y Luis Sánchez Laílla, Zaragoza, Institución Fernando el Católico, 2017, pp. 289-300.

Campos, Jorge, Teatro y sociedad en España (1780-1820), Madrid, Editorial Moneda y Crédito, 1969.

Cañas Murillo, Jesús, «Apostillas a una historia del teatro español del siglo XVIII», Anuario de Estudios Filológicos, XIII, 1990, pp. 53-63.

Cañas Murillo, Jesús, «Raquel, de Vicente García de la Huerta, en la tragedia neoclásica española», Anuario de Estudios Filológicos, 23, 2000, pp. 9-36.

Caso González, José Miguel, «Notas sobre la comedia histórica del siglo XVIII», en Coloquio internacional sobre el teatro español del siglo XVIII, Abano Terme, Piovan Editore, 1988, pp. 123-132.

Colmenares, Diego de, Historia de la insigne ciudad de Segovia y compendio de las historias de Castilla, edición digital, Alicante, Biblioteca Virtual Miguel de Cervantes, 1999 [1637]. En línea: <http://www.cervantesvirtual.com/obra/ historia-de-la-insigne-ciudad-de-segovia-y-compendio-de-las-historiasde-castilla--0/> [consultado el 13 de abril de 2020].

Chronica del famoso cauallero Cid Rui Diez Campeador, Burgos, imprenta de Felipe de Junta y Juan Bautista Varesio, 1593.

Cook, John A., Neo-classic Drama in Spain: Theory and Practice, University Park (Texas), Southern Methodist University Press, 1959.

Cronica del muy esforçado cauallero el Cid Ruy Diaz Campeador, Sevilla, imprenta de Juan Cromberger, 1533.

«Discurso sobre el origen, uso y abolición de los duelos en España», Memorial literario, Madrid, Imprenta Real, enero de 1785, pp. 95-100.

Durán López, Fernando, «Estudio preliminar», en José de Vargas Ponce, Los hijosdalgo de Asturias. Tragedia, Gijón, Trea, 2018, pp. 7-78.

Escalante Varona, Alberto, «Tratamiento literario de la figura de Fernán González: fuentes primarias y ediciones», Boletín de la Institución Fernán González, XCV, $252(2016 / 1), 2016$, pp. 97-116. 
Escalante Varona, Alberto, «Para una bibliografía de Fernán González. Actualizaciones en la evolución textual de un argumento literario», en Literatura Medieval (Hispánica): nuevos enfoques metodológicos y críticos, coord. Gaetano Lalomia y Daniela Santonocito, San Millán de la Cogolla, Cilengua, 2018, pp. 191-202.

Escalante Varona, Alberto, «Forner contra Laviano: la Carta de Marcial en su contexto (la respuesta erudita a los "copleros" de 1783)», Philologia Hispalensis, 33.2, 2019a, pp. 71-88.

Escalante Varona, Alberto, «De censuras y canon: la Historia verdadera de Fernán González y la recepción de la ficción caballeresca breve en los albores de la \|lustración», en Los inicios ilustrados de la historiografía literaria española: miradas sobre la Edad Media y el Siglo de Oro (1700-1833), ed. Jesús Cañas Murillo y José Roso Díaz, San Millán de la Cogolla, Cilengua, 2019b, pp. 89-110.

Escalante Varona, Alberto, «Calas críticas en la transmisión manuscrita del Cantar de mio Cid a partir de sus copias dieciochescas», Cuadernos dieciochistas, 20, 2019c, pp. 269-302.

Fernández Cabezón, Rosalía, Lances y batallas. Gaspar Zavala y Zamora y la comedia heroica, Valladolid, Aceña Editorial, 1990.

Frenzel, Elisabeth, Vom Inhalt der Literatur. Stoff-Motiv-Thema, Friburgo, Herder, 1980.

García Collado, María Ángeles, Los libros de cordel en el Siglo Ilustrado. Un capítulo para la historia literaria en la España Moderna, tesis doctoral, Vitoria, Universidad del País Vasco, 1997.

García Collado, María Ángeles, «Lectura y edición popular en la España ilustrada: las colecciones del impresor Manuel Martín», Cuadernos de Ilustración y Romanticismo, XXIII, 2017, pp. 155-172.

Gómez Pérez, José, «Una crónica de Fernán González escrita por orden del emperador Carlos V», Revista de Archivos, Bibliotecas y Museos, 64.2, 1958, pp. 551-581.

Infantes, Víctor, «Fingir la historia. La Colección de varias historias de Hilario Santos Alonso y Manuel Joseph Martín (1767-1780), un testimonio editorial de (re) escritura literaria», Historias fingidas, II, 2014, pp. 25-48.

«La conquista de Madrid por el rey don Ramiro, y el Conde Fernán-González. Comedia», Memorial literario, Madrid, Imprenta Real, marzo de 1786, p. 499.

Lopez, François, «Antonio Sanz, imprimeur du roi et l'édition populaire sous l'Ancien Régime», Bulletin Hispanique, XCV, 1, 1993, pp. 349-378.

López Martín, Ismael, «La pervivencia de un canon neoclásico heredado: Lope de Vega a la luz del Theatro Hespañol de Vicente García de la Huerta», en Vicente García de la Huerta y su obra (1734-1787), ed. Jesús Cañas Murillo, José Roso Díaz y Miguel Ángel Lama Hernández, Madrid, Visor, 2015, pp. 319-343. 
López Martín, Ismael, «Los tratados de poética del siglo XVIII y el tratamiento de dos figuras clave en el barroco español: Lope de Vega y Calderón de la Barca», en Los inicios ilustrados de la historiografía literaria española: miradas sobre la Edad Media y el Siglo de Oro (1700-1833), ed. Jesús Cañas Murillo y José Roso Díaz, San Millán de la Cogolla, Cilengua, 2019, pp. 305-321.

Lorenzo Álvarez, Elena de, «Estudio preliminar», en Gaspar Melchor de Jovellanos, El Pelayo. Tragedia, Gijón, Trea, 2018, pp. 13-152.

McClelland, Ivy L., Spanish Drama of Pathos, 1750-7800. I: High Tragedy. II: Low Tragedy, Liverpool, Liverpool University Press, 1970.

Menéndez Pidal, Ramón, El rey Rodrigo en la literatura, Madrid, Tipografías de la Revista de Archivos, Bibliotecas y Museos, 1924.

Narganes, David, Luis Moncín y la comedia de moros y cristianos, Madrid, Cultiva, 2010.

Palacios Fernández, Emilio, «El teatro en el siglo XVIII (hasta 1808)», en Historia del teatro en España. II. Siglos XVIII-XIX, coord. José María Díez Borque, Madrid, Taurus, 1988, pp. 57-376.

Palacios Fernández, Emilio, «El teatro popular», en El teatro en la España del siglo XVIII. Homenaje a Josep Maria Sala Valldaura, ed. Judith Farré, Nathalie Bittoun-Debruyne y Roberto Fernández, Lleida, Edicions de la Universitat de Lleida, 2012, pp. 159-176.

Pedraza Jiménez, Felipe B., «Donde hay amor no hay celos: un éxito olvidado», en Estudios sobre Rojas Zorrilla, [Cuenca], Universidad de Castilla-La Mancha, 2007, pp. 277-301.

Pérez Priego, Miguel Ángel, «Actualizaciones literarias de la leyenda de Fernán González», en La leyenda. Antropología, historia, literatura. Actas del coloquio celebrado en la casa de Velázquez, coord. Jean-Pierre Étienvre, Madrid, Universidad Complutense de Madrid, 1989, pp. 238-252.

Puyol y Alonso, Julio, La crónica popular del Cid, Madrid, Librería General de Victoriano Suárez, 1911.

Quintanilla, Mariano, «Crónica de Fernán González», Estudios Segovianos, VI, 18, 1954, pp. 495-506.

Ratcliffe, Marjorie, «El teatro épico en el siglo XVIII español. El Cid y Fernán González en dos dramas de Manuel Fermín de Laviano», Dieciocho. Hispanic enlightenment, 25.2, 2002, pp. 7-200.

Rodiek, Christoph, La recepción internacional del Cid, versión española de Lourdes Gómez de Olea, Madrid, Gredos, 1995.

Rubio Jiménez, Jesús, El conde de Aranda y el teatro, Zaragoza, Ibercaja, 1998.

Sala Valldaura, Josep Maria, De amor y política. La tragedia neoclásica española, Madrid, CSIC, 2005. 
Sánchez, Tomás Antonio, Colección de poesías castellanas anteriores al siglo XV, tomo I, Madrid, Imprenta de Antonio de Sancha, 1779.

Torrecilla, Jesús, Guerras literarias del XVIII español. La modernidad como invasión, Salamanca, Universidad de Salamanca, 2008.

Vaquero, Mercedes, Vida rimada de Fernán González, Exeter, Universidad de Exeter, 1987.

Vega García-Luengos, Germán, «El Cid en el teatro de los Siglos de Oro. Las múltiples caras de una figura persistente», en El Cid en el teatro de los Siglos de Oro. Catálogo de la exposición organizada por el Instituto Castellano y Leonés de la Lengua. Burgos, de mayo a julio de 2007, Burgos, Instituto Castellano y Leonés de la Lengua, 2007, pp. 49-78. 